\title{
Risba kot orodje za vpogled v matematično razumevanje
}

\author{
Alenka Lipovec* in Manja Podgoršek
}

Oddelek za razredni pouk, Pedagoška fakulteta, Univerza v Mariboru

Povzetek: Vizualne reprezentacije omogočajo osmišljanje pomena matematičnih pojmov, odnosov in procesov, zato imajo pomembno vlogo pri pouku matematike. V predstavljeni raziskavi smo pri udeležencih preučevali razumevanje osnovnih matematičnih pojmov s pomočjo risb. Pojem je bil podan v simbolni obliki (npr. 17 - 9), udeleženci pa so ga morali prikazati z risbo. Zanimalo nas je, ali dijaki oz. študenti in bodoči učitelji $(N=345)$ ustrezno (v skladu z matematično definicijo) narišejo podani matematični pojem. Podatke smo obdelali s kombinacijo kvantitativne in kvalitativne metodologije. Rezultati so pokazali, da udeleženci zahtevane pojme z risbo ustrezno prikazujejo, pri čemer je delež ustreznosti risb v povezavi z abstraktnostjo prikazanega pojma. Ugotovili smo tudi, da študenti 4. letnikov, ki se izobražujejo za poučevanje na razredni stopnji, pozitivno izstopajo. Po pregledu vzorca risb smo na osnovi vsebinske analize oblikovali dve temi, ki prikazujeta dva načina matematičnega razumevanja (instrumentalno in relacijsko) oz. dva tipa matematičnega znanja (proceduralni in pojmovni). Izsledki raziskave lahko služijo raziskovalcem pri oblikovanju novih raziskovalnih instrumentov za merjenje matematičnega razumevanja in učiteljem pri izbirah načina vpogleda $v$ učenčevo razumevanje.

Ključne besede: matematika, razumevanje, vizualizacija, risba, poučevanje

\section{Drawing as a tool for an insight into mathematical understanding}

\author{
Alenka Lipovec* and Manja Podgoršek \\ Department of Elementary Education, Faculty of Education, University of Maribor, Slovenia
}

\begin{abstract}
Visual representations allow us to interpret the meanings of mathematical concepts, relationships and processes, therefore they play an important role in mathematics education. In the present study, we analysed participants' understanding of basic mathematical concepts through drawings. Symbolic representation of mathematical concept was provided (e.g., 17 - 9) to participants and they were asked to represent the given concept through a picture. We were interested if high school students and future teachers $(N=345)$ adequately (in accordance with mathematical definition) depicted given mathematical concept. The data were analysed using a combination of qualitative and quantitative analyses. The results show that participants quite adequately depicted basic mathematical concepts. Less abstract concepts were depicted more accurately. It was also noted, that $4^{\text {th }}$ year students, studying to teach at primary level, have performed better than others. In qualitative content analysis two themes emerged. Those themes illustrate two ways of mathematical understanding (instrumental and relational) and two types of mathematical knowledge (procedural and conceptual). The research results can serve researchers in the creation of new research instruments for measuring mathematical understanding and help teachers to find new approaches that will offer them an insight into students' mathematical understanding.
\end{abstract}

Keywords: mathematics, understanding, visualisation, drawings, teaching

\footnotetext{
*Naslov/Address: dr. Alenka Lipovec, Oddelek za razredni pouk, Pedagoška fakulteta, Univerza v Mariboru, Koroška c. 160, 2000 Maribor, e-pošta: alenka.lipovec@um.si
}

Članek je licenciran pod pogoji Creative Commons Attribution 4.0 International licence (CC-BY licenca).

The article is licensed under a Creative Commons Attribution 4.0 International License (CC-BY license). 
Risbe predstavljajo pogosto uporabljeno raziskovalno orodje na različnih področjih. V psihologiji je znan Rorschachov test (Šali, 1961), ki je namenjen temu, da lahko na osnovi udeleženčevega opisa predloge s črno packo ocenimo stil njegovega kognitivnega strukturiranja, s čimer lahko ocenimo nekatere značilnosti osebnosti posameznika. $\mathrm{Na}$ osnovi otroških risb (npr. človeška figura kot glavonožec) lahko psihologi tudi sklepajo, na kateri razvojni stopnji je otrok (Marjanovič Umek, 2011). Tudi družboslovna raziskovalna področja risbo vedno pogosteje uporabljajo kot raziskovalno orodje (npr. Kearney in Hyle, 2004; Saban in Akbulut, 2012). Guillemin (2004) je uporabil risbe žensk v srednjih letih kot orodje za vpogled v njihovo razumevanje lastnih zdravstvenih stanj (srčnih obolenj, menopavze). Rose (2014) meni, da je porast uporabe vizualnih raziskovalnih metod, ki temeljijo na uporabi slikovnih podatkov, posledica razvoja tehnologije. Posebej pri otrocih je risanje večkrat uporabljeno zaradi neposredne komunikacije, ki jo le-ta omogoča. Eldén (2012) je v svoji raziskavi analiziral otroške risbe in ugotovil, da so lahko dober vir podatkov. Otroku je podal navodilo, naj nariše svoj običajen dan, nato pa je z njim izvedel intervju, ki je bil osredotočen na odnose med osebami, ki so bile narisane. V drugem delu so otroci na sredino lista narisali sebe, v koncentrične kroge okrog pa osebe, ki so zanj pomembne. Ljudje, ki so bili otrokom bolj pomembni, so bili narisani bližje sredini. Primerjava risb in intervjujev je pokazala, da informacije, ki jih je bilo možno razbrati iz risb, in tiste, ki jih je otrok povedal, sicer niso popolnoma sovpadale, kljub temu pa so risbe ponujale dovolj dober vpogled $\mathrm{v}$ odnose otroka in pomembnih ljudi iz njegovega okolja. Tudi v Sloveniji so se na področju didaktike matematike risbe pokazale kot uporabno orodje za preverjanje stereotipov (npr. matematiki so moškega spola), ki jih imajo učenci o matematikih. Antolin Drešar in Lipovec (2015) ter Černela (2014) so na osnovi raziskave Picker in Berry (2000) ugotavljali, kakšen je pogled slovenskih učencev na poklic matematika. Risbe matematika, ki so jih narisali učenci, so prikazovale več tipov učitelja matematike, in sicer: izjemno nadarjen matematik, raztreseni matematik in matematik, ki ne zna učiti. Rezultati te raziskave so zanimivi, vendar ne ponujajo vpogleda v matematično znanje učencev.

Osnovne matematične pojme večkrat prikazujemo na različne načine, npr. s konkretnim materialom, sliko ali simboli. Po Brunerju razlikujemo tri osnovne tipe prikazov pojmov: enaktivno, ikonično in simbolno reprezentacijo pojmov. »Enaktivna reprezentacija je način predstavitve preteklih dogodkov skozi ustrezne motorične odzive. Ikonična reprezentacija povzame dogodke s selektivno organizacijo čutov in slik skozi prostorske, časovne in kvalitativne strukture učenčevega zaznavnega polja. Slike predstavljajo čutno zaznavne dogodke na smiseln družbeno dogovorjen način. Simbolna reprezentacija predstavlja pojme skozi značilnosti, ki vključujejo abstraktnost in splošnost.« (Bruner, 1964, str. 2).

Grafične reprezentacije, ki jih uvrščamo med ikonične reprezentacije, pri matematiki pogosto uporabljamo $\mathrm{v}$ obliki slik, risb, diagramov in tabel. Predstavljajo pa tudi pomembno sredstvo sporazumevanja za nekatera področja matematike (npr. geometrija, teorija grafov ...). Pomen risb za matematično razumevanje je najbolj očiten na področju geometrije, kjer lahko na risanje gledamo celo kot na obliko utelešenega razmišljanja (angl. embodied cognition), saj risba ne predstavlja zgolj končnega produkta misli, temveč misel samo (Thom in McGarvey, 2015). Kljub temu matematična skupnost pogosto dojema risbo $\mathrm{v}$ geometriji kot ne dovolj rigorozno obliko argumentacije, saj je risba (običajno poimenovana kot skica) lahko zavajajoča. Znan primer, kjer risba zavaja, je napačna vizualna argumentacija, ki vodi v trditev, da je vsak trikotnik enakostraničen (Maxwell, 1995). Ob dokazovanju trditve, da je vsak trikotnik enakostraničen, nas $\mathrm{v}$ tem primeru slika trikotnika, ki jo opazujemo ob dokazu, zavede. Opazujemo namreč konkreten trikotnik (npr. ostrokotni raznostranični trikotnik) ter (napačno) predpostavimo, da nekatere točke ležijo znotraj trikotnika oz. stranice, čeprav to v poljubnem trikotniku ne drži nujno. Kljub temu pa so korektni vizualni dokazi oz. »dokazi brez besed « pridobili na veljavi tudi znotraj matematike (Nelsen, 2000).

Vizualizacija in vizualne reprezentacije matematičnih pojmov znotraj pouka matematike raziskovalcem predstavljajo bogato raziskovalno področje. Vizualizacijo opredelimo kot spontano prepoznavo matematičnih odnosov v grafični predstavitvi. Pojem vizualna reprezentacija uporabljamo v različnih kontekstih, npr. statične grafične reprezentacije (slike, sheme, prikazi ...), dinamične grafične reprezentacije (video, aplet ...) ter včasih tudi v kontekstu dejanske/ konkretne reprezentacije, ki jo zaznavamo na vizualnem nivoju. V nadaljevanju bomo kot grafične reprezentacije pojmovali le statične grafične reprezentacije.

Čeprav na tem področju obstaja mnogo raziskav, so izsledki še vedno precej nekonsistentni. Nekatere raziskave so zaznale pozitivne učinke povečane uporabe grafičnih reprezentacij pri pouku matematike (Arcavi, 2003; Binterová, Petrášková in Komínková, 2014), v drugih raziskavah ni bilo mogoče zaznati ne pozitivnih ne negativnih učinkov (Sowell, 1989), nekatere raziskave pa so zaznale negativen vpliv, ki ga lahko imajo navodila, usmerjena $\mathrm{v}$ izdelavo skice, pri reševanju matematičnega problema (de Bock, van Dooren, Janssens in Verschaffel, 2007). Nekateri raziskovalci (Güler in Çiltaş, 2011) zato pozivajo učitelje k uporabi slikovnega materiala pri poučevanju matematike, drugi (Presmeg, 1992) pa menijo, da lahko pretirana uporaba slik povzroči odmik od bistva matematičnega problema, ker se učenec preveč osredotoči na nepomembne podrobnosti na sliki.

$\mathrm{V}$ zadnjem času se mnogo raziskav usmerja tudi $\mathrm{V}$ vizualizacijska orodja, ki so izdelana s pomočjo računalniške tehnologije, vendar so tudi rezultati s tega področja še nekonsistentni (Archer idr., 2014). Raziskave pričakovano poročajo o zaznanih razlikah učinkovitosti vizualnih reprezentacij glede na starost učencev, tako npr. English (1993) ugotavlja, da so drevesni prikazi oz. kombinatorična drevesa (grafični prikaz z vozlišči in prikazom vseh možnih izbir) lahko neprimerni za mlajše učence, vendar pa te iste prikaze lahko kasneje uporabljamo kot koristno in uporabno orodje (Beitzel, Staley in Dubois, 2011). V nekaterih raziskavah so bile zaznane tudi razlike med spoloma, kot na primer, da dečki bolje interpretirajo matematične grafične prikaze, podobne zemljevidom (Lowrie in Diezman, 2011). Učinkovitost vizualnih reprezentacij je odvisna tudi od vsebine, ki jo risbe predstavljajo. Raziskave 
nevrokognitivnih znanstvenikov poročajo o zaznani različni aktivnosti možganov ob matematičnih aktivnostih z različnih vsebinskih področij. Ugotavljajo, da je možganska aktivnost drugačna $\mathrm{V}$ primerih, ko imamo opravka $\mathrm{z}$ grafičnimi reprezentacijami iz vsebin algebre, kot pa $\mathrm{v}$ primerih, ko opazujemo narisane geometrijske objekte (Leikin, Waisman, Shaul in Leikin, 2014). Pretekle raziskave, ki so vključevale grafične reprezentacije na področju matematike, so bile usmerjene $\mathrm{v}$ različna matematična področja. $\mathrm{S}$ področja aritmetike najdemo raziskave, narejene na mlajših učencih, predvsem s področja zgodnjega razvoja številskih predstav in zgodnjih aritmetičnih operacij (Badillo, Font in Edo, 2015; Rivera, 2014).

Raziskave s tega področja (npr. Badillo idr., 2015) so bile večinoma zastavljene tako, da so od učencev zahtevale rešitev določenega problema. Učenci so se $\mathrm{v}$ procesu reševanja problema večkrat spontano odločili, da bodo problem rešili s pomočjo risbe. Če je bil takšen način reševanja učinkovit, je bilo odvisno od tipa naloge. Naloge, pri katerih učinkovit pristop reševanja vključuje jasen prikaz miselnega procesa skozi verbalni ali grafični prikaz, je Doerr (2006) poimenoval kot model sprožajoče naloge (angl. modell-ellicting tasks). Vendar tudi sprožajoče naloge same po sebi ne sprožijo nujno ustrezne reprezentacije. DiSessa (2004) se je zato osredotočil na razvoj metareprezentacijskih sposobnosti oz. sposobnosti učenca za prehajanje in ustrezno izbiranje učinkovitih reprezentacij. Tak pristop je značilen za pouk matematike v realističnem kontekstu (angl. RME - Realistic Mathematics Education), ki ga je razvil Freudenthal (1991) s sodelavci. Ker je osnova pristopa konstruktivistična, učenci oblikujejo lastne reprezentacije med reševanjem problemskih kontekstualiziranih besedilnih nalog (npr. Bakker in Gravemaijer, 2004; Doorman, 2002). Pristop, kjer modeli nastanejo iz kontekstualne situacije (angl. emergent modeling approach) tako, da jih konstruira učenec sam, je ena od ključnih značilnosti RME in predstavlja alternativo k poučevanju zuporabo vnaprej podanih grafičnih reprezentacij, ki jih izdela učitelj ali preferira matematična skupnost. Razvit je bil kot alternativa uporabe didaktičnih pripomočkov in slikovnih prikazov, ki naj bi najbolj učinkovito reprezentirali matematične pojme in jih zato pri pouku primarno predstavljamo. Zdi se, da se metareprezentacijske sposobnosti izboljšujejo, če učencem dovolimo oblikovanje lastnih risb in jih ne ukalupljamo z risbami, ki jih ponudi učitelj (Van den Heuvel-Panhuizen, 2003).

Matematika je abstraktna veda in se zato ukvarja predvsem z abstraktnimi pojmi. Mitchelmore in White (1995) pojasnjujeta več pomenov besede abstraktno in izpostavljata problematiko primanjkljaja raziskav s področja zgodnjega matematičnega izobraževanja. $\mathrm{V}$ našem prispevku bomo abstrakcijo razumeli kot odmik od konkretnega, pri čemer so nepomembne značilnosti zanemarjene. V začetnem izobraževanju ločujemo med empiričnim (izkustvenim) in teoretičnim/matematičnim (relacijskim) pristopom k usvajanju matematičnih pojmov. Čeprav oba pristopa izhajata iz izkušenjskega sveta učencev, empirični pristop vključuje opazovanje objektov in usvajanje pojma skozi proces empirične abstrakcije in posploševanja čutno zaznavnih skupnih značilnosti. Teoretični/matematični pristop pa zaznamuje opazovanje strukture različnih pojavov in dejavnosti ter usvajanje pojma skozi proces relacijske abstrakcije in posploševanja bistvenega odnosa (Kokol Voljč, 1995; Mitchelmore in White, 2004). Kot primer empiričnega pristopa vzemimo usvajanje števila (npr. 5), ki ga otrok dojame skozi iskanje podobnosti v mnogih situacijah, ki vključujejo skupine petih objektov. Matematični pojem krožnica sicer lahko poučujemo na podoben način, tj. z opazovanjem mnogih raznolikih situacij, v katerih nastopa, lahko pa je pristop bolj teoretično usmerjen $\mathrm{v}$ bistven odnos, ki ga karakterizira (konstantna razdalja med točko na krožnici in središčem). V tem primeru je dovolj, da uporabimo manjše število dejavnosti, ki ozavestijo ta odnos (npr. začrtovanje okrogle cvetlične grede z vrvico in količkom). Večino matematičnih pojmov lahko predstavljamo pri pouku teoretično ali empirično, vendar je na zgodnji stopnji izobraževanja poudarek na empiričnem pristopu. Empirična abstrakcija predstavlja nižjo stopnjo abstrakcije kot relacijska abstrakcija in ne vodi k usvajanju bolj abstraktnih pojmov v matematiki. V matematiki nasploh so nekateri pojmi bolj abstraktni kot drugi, če je povezava z realnim (izkustvenim) svetom bolj oddaljena, saj so pojmi nastali skozi proces abstrahiranja in posploševanja iz abstraktnih miselnih objektov. Manj abstraktne pojme (npr. naravna števila in računske operacije z njimi) učenci spoznavajo prej kot bolj abstraktne (npr. racionalna števila in ekvivalentne ulomke). Učenci tako najprej razvijejo pojem naravnega števila in iz tega miselnega objekta šele pojem ulomka. Med predstavljenimi pojmi, uporabljenimi v naši raziskavi, je najmanj abstraktno odštevanje, ki mu sledijo prioritete računskih operacij, prikazane z oklepajem. Nekoliko bolj abstraktna pa sta potenca in ulomek, ki ju sestavlja odnos med dvema naravnima številoma (osnova in stopnja pri potenci in števec in imenovalec pri ulomku).

Skemp (1976) je matematično razumevanje pojasnjeval skozi dva tipa razumevanj; kot relacijsko in instrumentalno razumevanje, ki se nahajata na obeh polih kontinuuma razumevanja. Instrumentalno razumevanje je relativno siromašno $\mathrm{z}$ vidika povezav med pojmi, relacijsko razumevanje pa je tisto, ki je bogato tako $\mathrm{v}$ kvantiteti kot kvaliteti teh povezav. Skempov pogled je kasneje privedel do delitve matematičnega znanja na pojmovni in proceduralni tip znanja. Proceduralno znanje je opredeljeno kot znanje, ki ga uporabljamo v situacijah, ko po (enoličnih, natanko določenih) korakih rešujemo problem, medtem ko je pojmovno znanje opredeljeno kot znanje, pri katerem v kognitivni shemi obstaja mnogo povezav (Hiebert in LeFevre, 1986; Rittle-Johnson in Siegler, 1998). Kljub nekaterim zaznanim pomanjkljivostim delitve znanja na ta dva tipa (Star, 2005), sta navedena tipa matematičnega znanja, ki se oblikujeta tudi v naših rezultatih, široko raziskovana.

\section{Raziskovalni problem}

Vizualne reprezentacije (npr. risbe) lahko služijo kot orodje za reševanje (običajno kontekstualiziranega) problema, ki ga reševalec samostojno iznajde $\mathrm{v}$ postopku reševanja. Znotraj področja didaktike matematike pa še ni jasno, ali lahko tudi risbe, ki ne nastanejo v kontekstu reševanja kontekstualiziranega problema, predstavljajo vpogled v razumevanje matematičnega pojma. Zato naloga, ki smo jo uporabili za instrument v tej raziskavi, ne sodi med 
naloge, ki jih Doerr (2006) označuje kot model sprožajoče naloge. Namen naše raziskave je torej bil, da s pomočjo risb dijakov in študentov dobimo vpogled $v$ razumevanje podanih matematičnih pojmov, pri čemer smo uporabili kombinacijo kvantitativnih in kvalitativnih analiz. Za dober pouk matematike je namreč zelo pomembno, da se učitelj zaveda, kakšna je učenčeva stopnja razumevanja matematičnih pojmov. Cilji naše raziskave so bili:

1. Ugotoviti, ali udeleženci $\mathrm{z}$ risbo ustrezno prikazujejo zahtevani matematični pojem. Ustreznost prikaza bomo preverjali v smislu matematične ustreznosti (prim. slika 1).

2. Ugotoviti razlike $\mathrm{v}$ ustreznosti risb glede na vrsto matematičnega pojma in vrsto izobraževalnega programa udeležencev.

3. Oblikovati klasifikacijo risb, ki prikazujejo zahtevani matematični pojem.

$\mathrm{Na}$ osnovi pregleda literature smo pričakovali, (i) da bodo skoraj vse risbe ponazarjale zahtevane matematične pojme, saj so podani osnovni matematični pojmi (odštevanje, oklepaj, potenca in ulomek), (ii) da bodo razlike v ustreznosti risb povezane z zahtevnostjo pojma (stopnja abstrakcije) in vrsto izobraževanja in (iii) da bo klasifikacija risb ponudila vpogled v prevladujoč tip znanja udeleženca (pojmovni ali proceduralni).

\section{Metoda}

\section{Udeleženci}

V naši raziskavi so sodelovali dijaki in študenti. Vzorec je bil neslučajnostni priložnostni in je zajemal dijake prvih dveh letnikov ene od slovenskih splošnih gimnazij (142), študente 1. letnika programa Razredni pouk na Univerzi v Mariboru (90) in študente 4. letnika tega programa (117) ter študente zadnjega letnika enopredmetnih in dvopredmetnih študentov pedagoške matematike (56) na Univerzi v Mariboru. Bazen potencialnih udeležencev je torej sestavljalo 405 dijakov in študentov. Podatke smo pridobili od 345 dijakov oz. študentov, kar je predstavljalo $85 \%$ celotnega bazena. Udeleženci so se izobraževali v štirih različnih vrstah izobraževanja: začetek splošno gimnazijskega programa (130), začetek izobraževanja za bodoče učitelje razrednega pouka (73), zaključek izobraževanja za bodoče učitelje razrednega pouka (94), zaključek izobraževanja za bodoče učitelje matematike (48). Skupine udeležencev so bile izbrane tako, da so prikazovale različne tipe učiteljev matematike (razredne in predmetne učitelje) in dijake, ki se lahko vpisujejo na ta dva programa.

\section{Pripomočki in postopek}

Podatki so bili zbrani v študijskem letu 2013/14 s pomočjo preizkusa znanja, ki je obsegal 4 naloge, ki so se dotikale osnovnih matematičnih pojmov s področja aritmetike. Za aritmetiko smo se odločili, ker gre za eno od temeljnih področij matematike in ker pri njej vizualna komponenta ni tako močno izražena kot pri geometriji. Naloge so se nanašale na naslednje matematične pojme:
- odštevanje: odštevanje s prehodom v obsegu do 20,

- oklepaj: številski izraz z naravnimi števili in oklepaji,

- ulomek: izračunavanje dela celote in

- potenca: potenca $\mathrm{z}$ naravno osnovo in stopnjo.

Naloge so od dijakov oz. študentov zahtevale, da grafično ponazorijo zapisan številski izraz. Udeleženci so dobili bel A4 list, ki je bil razdeljen na štiri polja, tako da je imel vsak pojem prostor za risbo že predviden. Navodilo Narišite risbo je bilo zapisano na vrhu lista. V vsakem izmed polj je bil zapisan številski izraz, npr. v levem zgornjem polju je bil že zapisan izraz a). Navedeni so bili naslednji številski izrazi: a) $17-9$, b) $3 *(4+5)$, c) $3 / 5$ od 15 in d) $2^{3}$. Podano je bilo ustno navodilo: »Narišite risbe, ki prikazujejo vsakega izmed podanih izrazov.« Dodatnih navodil nismo dajali. Udeleženci so naloge reševali v šoli oz. na fakulteti v sklopu pouka matematike oz. v sklopu vaj iz didaktike matematike. Za reševanje so imeli na voljo 20 minut.

\section{Preliminarne analize}

Risbe smo pregledali in jih kategorizirali glede na to, ali so prikazovale ustrezen matematični pojem. Risba je bila kategorizirana kot ustrezna, če je prikazovala ikonično reprezentacijo zahtevanega matematičnega pojma. Risba je bila označena kot neustrezna, če je prikazovala drug matematični pojem ali pa ni bilo mogoče prepoznati, kaj modelira. Na sliki 1 so za dodatno pojasnitev kriterijev za določitev ustreznosti dodani primeri risb udeležencev. Podajamo le nekatere primere za izbrane kategorije izbranih pojmov. Slika 1 prikazuje primere risb iz kategorij Ustrezno (prikazan je zahtevan pojem) in Neustrezno (prikazan je drug pojem oz. pojma ni mogoče določiti). Na sliki la vidimo risbo, ki ustrezno ponazarja zahtevani matematični pojem $3 *(4+5)$. Risba prikaže relacije med števili in poudari pomen oklepaja. Primer neustrezne risbe najdemo na sliki $1 \mathrm{~b}$, kjer je potenca $2^{3}$ neustrezno prikazana kot množenje $3 * 2$ (slika 1b). Če iz risbe ni bilo možno razbrati prikazanega pojma, smo jo uvrstili v kategorijo Ni mogoče določiti in obravnavali kot neustrezno ( slika 1c prikazuje risbo potence).

Po klasifikaciji risb smo uporabili Cochranov Q-test za ugotavljanje razlik $\mathrm{v}$ ustreznosti glede na matematični pojem. V drugem delu smo iskali razlike v ustreznosti risb glede na izobraževalni program, ki ga udeleženec obiskuje. Kot metodo analize razlik smo izbrali $\chi^{2}$ preizkus, za mero velikosti učinka pa smo izbrali Cramerjev $V$ koeficient, pri čemer smo upoštevali, da je v primeru, ko imamo 3 skupine, velikost učinka majhna, če je $V$ manjši od 0,07 , srednja, če je $V$ med 0,07 in 0,21, ter velika, če je Cramerjev $V$ večji od 0,35. $\mathrm{V}$ tretjem delu je bila izvedena kvalitativna vsebinska analiza. Hsieh in Shannon (2005) opredeljujeta kvalitativno vsebinsko analizo kot raziskovalno metodo, pri kateri interpretiramo podatke skozi sistematični proces kodiranja in prepoznavanja tem ali vzorcev. Skozi proces kodiranja enot gradiva tako v zbranem gradivu iščemo značilne kode, pojme, ki ilustrirajo proučevani fenomen ter jih nato povežemo med seboj $\mathrm{v}$ kategorije ter teme, nakar oblikujemo teoretične pojasnitve (Zhang in Wildemuth, 2009). V samem postopku kodiranja je bila objektivnost zagotovljena s tem, da sta avtorici kodirali 


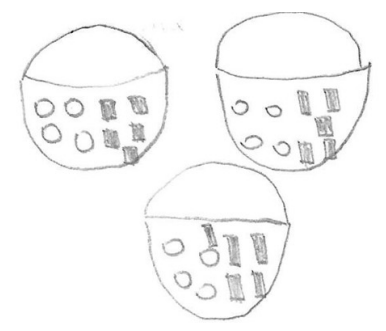

a)
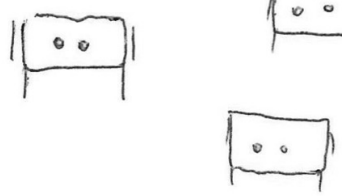

b)

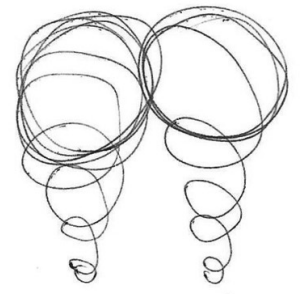

c)

Slika 1. Prikazi risb, ki prikazujejo a) zahtevan pojem (oklepaj), b) drug pojem (potenca) in c) ni mogoče določiti (potenca).

podatke individualno, morebitna razhajanja pa sta rešili prek diskusije. Pri procesu kodiranja smo uporabili induktivni pristop, kar pomeni, da si pred kodiranjem nismo pripravili seznama kod, temveč so se kode oblikovale iz podatkov med analizo besedila (Hesse-Biber in Leavy, 2004). Za podkrepitev same veljavnosti in zanesljivosti ugotovitev, nastalih med analizo podatkov, predstavljamo v nadaljevanju tudi konkretne primere, ki so jih narisali udeleženci naše raziskave.

\section{Rezultati}

$\mathrm{V}$ tem poglavju bomo predstavili rezultate o ustreznosti prikazanega matematičnega pojma in analizirali razlike med skupinami udeležencev. Nato bomo predstavili teme, kategorije in kode, ki so nastale pri kvalitativni vsebinski analizi.

Najprej nas je zanimalo, ali dijaki oz. študenti z risbo sploh ustrezno prikažejo zahtevan matematični pojem. Podatki o številu risb, ki so se pri danem pojmu pojavili v različnih kategorijah, so prikazani v tabeli 1.

Podatki v tabeli 1 prikazujejo, da so bili vsi pojmi v prevladujočem deležu ustrezno reprezentirani. Risbe so bile najbolj ustrezne pri odštevanju. Skoraj vsi udeleženci, 332 od 345, kar predstavlja $96 \%$ vzorca, so ustrezno prikazali 17 - 9. Najmanj ustrezne risbe so bile podane za ulomek. $\mathrm{V}$ tem primeru je ustrezno risbo podalo 252 udeležencev, kar predstavlja $73 \%$ vseh. Kot je razvidno iz tabele 1, pri odštevanju in pri izrazu z oklepaji ni bilo zaznati prikazov drugih matematičnih pojmov, medtem ko se to pojavi pri potenci in pri ulomku. Pri relativno velikem deležu risb ni bilo mogoče ugotoviti, kateri matematični pojem prikazujejo. Ugotovili smo tudi, da obstajajo statistično značilne razlike (Cochran $Q=95,583, p<0,001$ ) v ustreznosti risbe glede na matematični pojem.

Tabela 1. Ustreznost oz. neustreznost risb pri različnih matematičnih pojmih

\begin{tabular}{lcccccc}
\hline & Ustrezno & & \multicolumn{2}{c}{ Neustrezno } & & Skupaj \\
\cline { 2 - 3 } \cline { 6 - 6 } & $\begin{array}{c}\text { Zahtevan } \\
\text { pojem }\end{array}$ & & $\begin{array}{c}\text { Drug } \\
\text { pojem }\end{array}$ & $\begin{array}{c}\text { Ni mogoče } \\
\text { določiti }\end{array}$ & \\
& $f$ & & $f$ & $f$ & \\
\hline Odštevanje & 332 & & 0 & 13 & \\
Oklepaji & 311 & & 0 & 34 & & 345 \\
Potenca & 299 & & 24 & 22 & & 345 \\
Ulomki & 252 & & 66 & 27 & & 345 \\
\hline
\end{tabular}

Pri fiksnem matematičnem pojmu smo opazovali tudi razlike $\mathrm{v}$ ustreznosti prikazovanja matematičnega pojma glede na izobraževalni program, ki ga obiskujejo udeleženci. Podatke smo prikazali v tabeli 2.

Če se osredotočimo na razlike med skupinami udeležencev, lahko opazimo, da študenti, ki so v 4. letniku izobraževanja za poučevanje na razredni stopnji, $\mathrm{v}$ najvišji meri z risbo prikazujejo zahtevane matematične pojme. Pri odštevanju so vsi narisali ustrezno risbo, pri oklepaju je ustrezno risbo narisalo 90 študentov (95,7 \%), potenco je $\mathrm{z}$ ustrezno risbo prikazalo 88 študentov $(93,6 \%)$, ulomke pa 81 študentov $(86,2 \%)$. Delež ustreznih risb je bil najnižji pri študentih, ki se izobražujejo za poučevanje matematike. Ustrezno reprezentacijo odštevanja je podalo 42 študentov $(87,5$ \%), pri oklepaju je bilo teh študentov 39 (81,3\%), potenco je z ustrezno risbo prikazalo 40 študentov (83,3\%), 31 študentov je ustrezno prikazalo ulomek (64,6 \%). Statistično značilne razlike $\mathrm{v}$ ustreznosti risbe med udeleženci različnih programov smo zaznali pri vseh matematičnih pojmih (glej tabela 2) razen pri potenci. V velikosti učinka nismo zaznali bistvenih razlik. Cramerjev $V$ v vseh primerih zavzame vrednosti med 0,07 in 0,21, kar kaže, da je velikost učinka vrste matematičnega pojma, ne glede na vrsto izobraževanja, srednja.

V zadnji fazi smo se lotili analize zgolj tistih risb, ki so bile ustrezne. Risbam smo najprej dodelili kode, ki smo jih v nadaljevanju po načelu podobnosti združili v kategorije, lete pa smo nato po istem načelu združili v teme. Oblikovali sta se dve temi, ki smo ju poimenovali Proceduralno in Pojmovno, saj tipa znanja, ki ju ponazarjajo risbe, sovpadata s proceduralnim in pojmovnim tipom matematičnega znanja. Teme, kategorije in kode so prikazane v tabeli 3.

Podatke, prikazane $\mathrm{v}$ tabeli 3 , bomo $\mathrm{v}$ nadaljevanju ponazorili $\mathrm{s}$ pomočjo konkretnih primerov risb. Risbe (npr. slika 2a), kjer so bila števila prikazana s slikovnimi ponazoritvami objektov, računske operacije med njimi pa so prikazane s simboli, so se pojavljale zelo pogosto. Te risbe smo umestili v skupno kategorijo Prepletanje simbolov in slik. Na sliki 2a tako vidimo izraz $3 *(4+5)$, pri čemer so številke 3, 4 in 5 nadomeščene $\mathrm{z}$ ustreznim številom krogcev, računski operaciji seštevanja in množenja pa sta prikazani $s$ simboloma $\cdot$ in +. Mnoge risbe so prikazovale le rezultat, ki ga dobimo, ko izvedemo računske operacije. Rezultat, ki je bil prikazan kot določeno število objektov, smo poimenovali Slikovni rezultat (npr. risba osmih jabolk), rezultat, ki je bil prikazan s številko, pa smo poimenovali Simbolni rezultat. Številko so udeleženci večkrat preoblikovali v risbo nekega 
Tabela 2. Razlika v ustreznosti prikazovanja matematičnega pojma glede na vrsto izobraževanja

\begin{tabular}{|c|c|c|c|c|}
\hline & Vrsta izobraževalnega programa udeležencev & $\begin{array}{c}\text { Ustrezno } \\
f\end{array}$ & $\begin{array}{c}\text { Neustrezno } \\
f\end{array}$ & $\begin{array}{c}\text { Skupaj } \\
f\end{array}$ \\
\hline \multirow[t]{6}{*}{ Odštevanje } & Dijaki splošne gimnazije & 124 & 6 & 130 \\
\hline & Bodoči učitelji razrednega pouka, 1. letnik & 72 & 1 & 73 \\
\hline & Bodoči učitelji razrednega pouka, 4. letnik & 94 & 0 & 94 \\
\hline & Bodoči učitelji matematike & 42 & 6 & 48 \\
\hline & Skupaj & 332 & 13 & 345 \\
\hline & & \multicolumn{3}{|c|}{$\chi^{2}(3)=15,382, p=0,002$, Cramerjev $V=0,21$} \\
\hline \multirow[t]{6}{*}{ Oklepaj } & Dijaki splošne gimnazije & 114 & 16 & 130 \\
\hline & Bodoči učitelji razrednega pouka, 1. letnik & 68 & 5 & 73 \\
\hline & Bodoči učitelji razrednega pouka, 4. letnik & 90 & 4 & 94 \\
\hline & Bodoči učitelji matematike & 39 & 9 & 48 \\
\hline & Skupaj & 311 & 34 & 345 \\
\hline & & \multicolumn{3}{|c|}{$\chi^{2}(3)=9,215, p=0,027$, Cramerjev $V=0,16$} \\
\hline \multirow[t]{6}{*}{ Potenca } & Dijaki splošne gimnazije & 108 & 22 & 130 \\
\hline & Bodoči učitelji razrednega pouka, 1. letnik & 63 & 10 & 73 \\
\hline & Bodoči učitelji razrednega pouka, 4. letnik & 88 & 6 & 94 \\
\hline & Bodoči učitelji matematike & 40 & 8 & 48 \\
\hline & Skupaj & 299 & 46 & 345 \\
\hline & & \multicolumn{3}{|c|}{$\chi^{2}(3)=5,849, p=0,119$, Cramerjev $V=0,13$} \\
\hline \multirow[t]{6}{*}{ Ulomki } & Dijaki splošne gimnazije & 92 & 38 & 130 \\
\hline & Bodoči učitelji razrednega pouka, 1. letnik & 48 & 25 & 73 \\
\hline & Bodoči učitelji razrednega pouka, 4. letnik & 81 & 13 & 94 \\
\hline & Bodoči učitelji matematike & 31 & 17 & 48 \\
\hline & Skupaj & 252 & 93 & 345 \\
\hline & & \multicolumn{3}{|c|}{$\chi^{2}(3)=12,283, p=0,006$, Cramerjev $V=0,19$} \\
\hline
\end{tabular}

Opomba: V primerih, ko je bila vsaj ena teoretična frekvenca manjša od 5, smo za oceno statistične pomembnosti učinka uporabili Monte Carlo postopek (s privzetimi nastavitvami v programu SPSS).

objekta. Na sliki 2 b tako vidimo številko 8 , preoblikovano v snežaka. Kategorije Slikovni rezultat, Simbolni rezultat in Prepletanje karakterizirajo proceduralni pristop, ki teži k pridobivanju rezultata. Zato smo te kategorije združili v temo Proceduralno.

Vse kode (pri vseh pojmih), ki so prikazovale odnose/ relacije med števili v številskem izrazu, smo umestili v temo Pojmovno. V teh risbah je rezultat sicer razviden, vendar prevladuje pojmovni vidik. Pri odštevanju so se npr. relacije med števili 17,9 in 8 lahko izražale skozi črtanje objektov, ki so ponazarjali odštevanec, sama risba pa je prikazovala tako zmanjševanec kot odštevanec in razliko. Risbe odštevanja so običajno prikazovale 17 objektov (zmanjševanec), od katerih jih je bilo 9 prečrtanih. Primere risb iz kategorije Pojmovno najdemo npr. tudi na slikah 1a in 2c. Na sliki la vidimo prikazane odnose med števili 3, 4 in $5 \mathrm{v}$ izrazu z oklepaji, na sliki 2c pa vidimo primer, kjer je odnos med števili 3, 5 in 15 v izrazu z ulomkom jasno razviden. Primeri za potenco so prikazani na sliki 3 in jih bomo zato komentirali ločeno. Pri ulomkih sta se dodatno pojavila dva modela za prikazovanje ulomka, ki sta oblikovala dve kodi: kodo Aritmetični model zaznamuje prikaz števne množice petnajstih objektov (npr. slika 2c), kodo Geometrijski model pa zaznamuje prikaz geometrijske oblike (običajno enega kroga).
Nekatere risbe, ki prikazujejo le »okrašen«, oz. ilustriran izraz, ki pa je dopolnjen $\mathrm{z}$ risbo, smo umestili v kategorijo Ilustracija. $\mathrm{Na}$ sliki $2 \mathrm{~d}$ vidimo primer izraza $2^{3}$, kjer številko 2 predstavljata dva sladoleda, številko 3 pa trije okvirčki, ki so tudi prostorsko umeščeni kot stopnja. V teh primerih ni bilo mogoče določiti proceduralne oz. pojmovne naravnanosti risbe, zato se je oblikovala še kategorija $\mathrm{Ni}$ mogoče prepoznati.

Pri potenci je bil nabor različnih kod posebej bogat, zato jih prikazujemo posebej na sliki 3. Risbe iz kode Drevesni prikaz (3a) ponazarjajo potenco s pomočjo drevesnega diagrama oz. kombinatoričnega drevesa. Drugi način, prikazan na sliki 3b, smo poimenovali Ugnezdena struktura. Gre za risbo, ki ponazarja dve polici z dvema skledama, v vsaki izmed skled pa sta dva predmeta. Prikaz na sliki 3c poimenovan Kocka, prikazuje kocko, pri čemer je potenca lahko prikazana skozi število oglišč ali skozi volumen kocke, če je podan rob 2 . 
Tabela 3. Teme, kategorije in kode risb matematičnih pojmov

\begin{tabular}{|c|c|c|c|c|c|}
\hline \multirow[b]{2}{*}{ Teme } & \multirow[b]{2}{*}{ Kategorije } & \multicolumn{4}{|c|}{ Kode } \\
\hline & & Odštevanje & Oklepaji & Potenca & Ulomek \\
\hline \multirow[t]{3}{*}{ Proceduralno } & Simbolni rezultat & Številka 8 & Številka 27 & Številka 8 & Številka 9 \\
\hline & Slikovni rezultat & 8 predmetov & 27 predmetov & 8 predmetov & 9 predmetov \\
\hline & Prepletanje & \multicolumn{4}{|c|}{$\begin{array}{l}\text { Slikovni prikaz objektov je prepleten s prikazom matematičnih simbolov (npr. } \\
\text { ulomkova črta). } \\
\text { Slika 2a }\end{array}$} \\
\hline \multirow[t]{2}{*}{ Pojmovno } & Odnosi & $\begin{array}{l}\text { Objekti, ki } \\
\text { ponazarjajo } \\
\text { odštevanec, so } \\
\text { prečrtani. }\end{array}$ & $\begin{array}{l}\text { Ponazoritev } \\
\text { različnih } \\
\text { seštevancev. } \\
\text { Slika la }\end{array}$ & $\begin{array}{l}\text { Drevesni } \\
\text { prikaz } \\
\text { Slika } 4 a\end{array}$ & $\begin{array}{l}\text { Aritmetični model } \\
\text { Slika } 2 b\end{array}$ \\
\hline & & & $\begin{array}{l}\text { Brez } \\
\text { ponazoritve } \\
\text { različnih } \\
\text { seštevancev. }\end{array}$ & $\begin{array}{l}\text { Ugnezdena } \\
\text { struktura } \\
\text { Slika 4b } \\
\text { Kocka } \\
\text { Slika 4c }\end{array}$ & Geometrijski model \\
\hline $\begin{array}{l}\text { Tipa ni mogoče } \\
\text { prepoznati }\end{array}$ & Ilustracija & \multicolumn{4}{|c|}{$\begin{array}{l}\text { Številski izraz je »okrašen« s slikovnimi dodatki. } \\
\text { Slika 2c }\end{array}$} \\
\hline
\end{tabular}

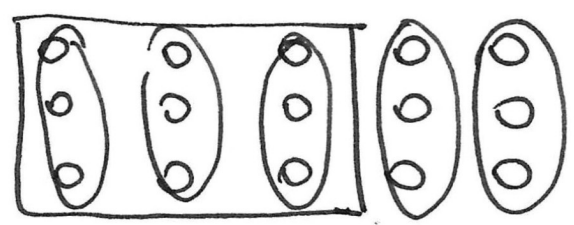

c)

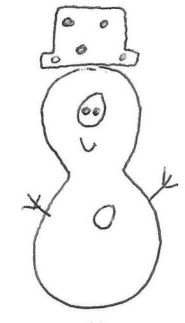

b)

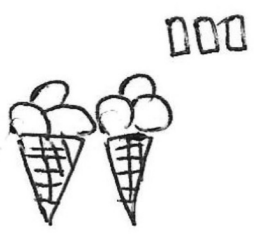

d)

Slika 2. Slikovni primeri tem, ki smo jih uporabili: a) proceduralno (oklepaji), b) proceduralno (odštevanje), c) pojmovno (ulomek) in d) ni mogoče prepoznati (potenca).

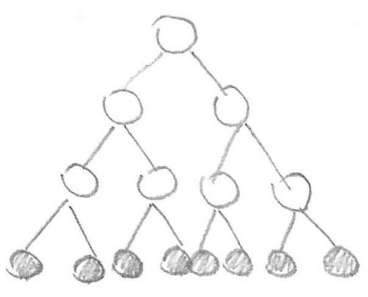

a)

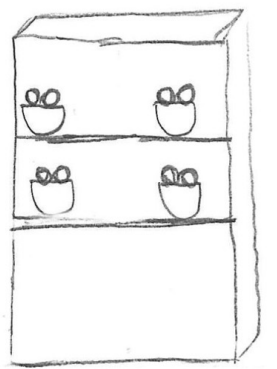

b)

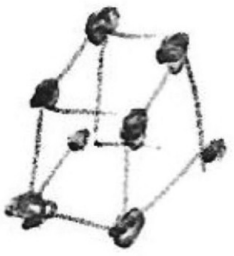

c)

Slika 3. Primeri risb potence za kode a) drevesni prikaz, b) ugnezdena struktura in c) kocka. 


\section{Razprava}

Prvi cilj naše raziskave je bil ugotoviti, ali udeleženci $\mathrm{z}$ risbo ustrezno prikazujejo zahtevani matematični pojem. Ugotovili smo, da so skoraj vse risbe udeležencev prikazovale zahtevani matematični pojem in s tem potrdili prvo pričakovanje. V nadaljevanju smo poskušali ugotoviti, kako vrsta matematičnega pojma določa ustreznost risbe. Rezultati so pokazali, da udeleženci $\mathrm{v}$ večini primerov $\mathrm{v}$ večjem deležu ustrezno prikazujejo matematično operacijo odštevanja ter številski izraz $\mathrm{z}$ oklepaji, medtem ko sta potenca in izraz z ulomkom manj ustrezno prikazovana. Rezultati potrjujejo predpostavko, da abstraktnost pojma vpliva na ustreznost risbe. Manj abstraktni pojmi so $\mathrm{z}$ risbo prikazani bolj ustrezno. Abstraktnost se v skladu z opredelitvijo, ki jo podajata Mitchelmor in White (2004), in relacijskim razumevanjem (Skemp, 1976) izraža tudi v številu pojmov, ki so potrebni za oblikovanje novega matematičnega pojma. Konkretno to pomeni, da je npr. limita funkcije bolj abstrakten pojem od funkcije, saj ta predstavlja pogoj za razvoj pojma limite. $\mathrm{V}$ našem primeru je najmanj abstrakten pojem odštevanje, ki mu sledi oklepaj, potenca in ulomek pa sodita med bolj abstraktne pojme na razredni stopnji. Na podlagi ugotovljenega lahko potrdimo prvi del drugega pričakovanja, ki govori o povezanosti med zahtevnostjo (stopnjo abstrakcije) pojma in ustreznostjo risb. Naši rezultati torej potrjujejo, da je razumevanje manj abstraktnih pojmov bolj poglobljeno, kar je v skladu z ugotovitvami Pirie in Kieren (1994), ki povzemata ugotovitve mnogih empiričnih in teoretičnih spoznanj v didaktiki matematike. Tudi diSessa (2004) trdi, da bolj poglobljeno razumevanje učencu omogoča boljše metareprezentativne sposobnosti in s tem tudi izbiro ustreznega načina reprezentiranja.

Drugi del drugega pričakovanja se je nanašal na povezanost ustreznosti risb in vrste izobraževanja. Iz rezultatov je razvidno, da povezanost obstaja. Naši rezultati kažejo na razlike v ustreznosti prikazovanja pojma glede na vrsto izobraževalnega programa, ki ga obiskujejo udeleženci, kar nam omogoča, da potrdimo tudi drugi del drugega pričakovanja. Najbolj ustrezno so pojme prikazovali bodoči učitelji razrednega pouka, najmanj ustrezno pa bodoči učitelji matematike. Tudi dijaki splošne gimnazije so matematične pojme prikazali $\mathrm{v}$ relativno visokem deležu. Njihovo uspešnost povezujemo z dejstvom, da gre, predvsem zaradi zahtevnosti splošnega gimnazijskega programa, za dobre učence, ki osnovne matematične pojme dobro razumejo. Relativno uspešnost bodočih razrednih učiteljev povezujemo z njihovim izobraževanjem, ki poudarjeno razvija znanje za poučevanje (angl. Pedagogical Content Knowledge) oz. matematično znanje za poučevanje (angl. Mathematical Knowledge for Teaching). Gre za posebno znanje, ki ga učitelji potrebujejo pri svojem poklicu in se nanaša na sposobnost učitelja, da pretvori vsebino v takšno obliko, ki je pedagoško in didaktično ustrezna ter je prilagojena razlikam v sposobnostih in predznanju študentov. To znanje (Ball, Thames in Phelps, 2008) učitelje razlikuje od znanstvenikov in je povezano z znanjem, ki ga izkazujejo učenci (Hill, Rowan in Ball, 2005). Matematično znanje za poučevanje predmetnega učitelja je seveda drugačno kot matematično znanje za poučevanje razrednega učitelja. Na nižjih stopnjah so grafične reprezentacije poudarjene v večji meri, saj je takrat risanje risb bolj sprejemljiva oblika poučevanja. Spoznanja o stopnjah reprezentacij (npr. Brunerjeve reprezentacije) se pri mlajših učencih implementirajo v pouk pogosteje kot na višjih stopnjah izobraževanja. Te poudarke upoštevajo tudi programi za izobraževanje učiteljev na razredni stopnji. Kasneje postane pouk usmerjen $\mathrm{v}$ bolj matematizirane reprezentacije, kot so diagrami, tabele, grafi, ki so značilne za simbolno reprezentacijo. Nekateri avtorji (Bakker in Gravemeijer, 2004) opozarjajo na to, da se mora pouk matematike tudi v kasnejših letih povezovati s konkretnimi situacijami, če ga želimo osmisliti pri učencih. V tem kontekstu poudarjajo pomen risb, ki jih generira učenec sam, tudi pri oblikovanju matematičnih pojmov v srednji šoli.

Dodatno naši rezultati nakazujejo, da sta za bodoče učitelje potenca in ulomek nekoliko težja za ustrezno reprezentacijo kot pa odštevanje in oklepaj. Tudi v nekaterih drugih raziskavah je mogoče najti podatke o tem, da imajo sami učitelji težave $\mathrm{z}$ razumevanjem ulomkov (Isik in Kar, 2012; Dixon idr., 2014) in potence (Confrey in Smith, 1995). Težave učiteljev se pojavijo že pri čisto elementarnih nalogah z ulomki, kot npr. »Pobarvaj 1/4 od podanega lika.« (Van Steenbrugge, Lesage, Valcke in Desoete, 2014; Depaepe idr., 2015). Lipovec in Ferk (2012) ugotavljata, da so na področju ulomkov slovenski bodoči učitelji matematike $\mathrm{v}$ primerjavi z ameriškimi izkazali dokaj dobro matematično znanje za poučevanje.

Tretji cilj raziskave govori o tem, da je možno risbe klasificirati. Predpostavili smo, da bo tip znanja spremenljivka, na osnovi katere se bodo oblikovale kategorije risb. Kot smo pričakovali, sta se znotraj kvalitativne vsebinske analize oblikovali dve prevladujoči temi risb, ki sta s svojimi značilnostmi sovpadali $\mathrm{s}$ proceduralnim in pojmovnim tipom matematičnega znanja, kar potrjuje tudi tretjo predpostavko. Čeprav kognitivni pristopi k matematičnem izobraževanju enakovredno poudarjajo tako pojmovni kot proceduralni tip znanja, še vedno obstaja odprto vprašanje o tem, kako definirati in meriti ta dva tipa znanja (RittleJohnson, Schneider in Star, 2015). Različne pristope k merjenju pojmovnega znanja sta predlagali Crooks in Alibali (2014). Naša raziskava je pokazala, da so lahko tudi risbe dober pokazatelj pojmovnega ali proceduralnega znanja. Proceduralno znanje se je skozi risbe izražalo kot poudarjen prikaz postopkov oz. algoritmov. Relativno visoka prisotnost tega tipa znanja je v skladu s spoznanji avtorjev, ki opisujejo pouk matematike v slovenskem prostoru. Levstek, Bregant in Podlesek (2013, str. 119) npr. ugotavljajo, da se »z vstopom otrok v izobraževalni sistem učenje aritmetike spremeni $\mathrm{v}$ učenje algoritmov, katere otroci izvajajo po spominu in jih avtomatizirajo.« Lipovec, Podgoršek in Antolin Drešar (2015) so izvedle podobno raziskavo na večjem številu osnovnošolcev in ugotovile, da proceduralno znanje močno prevladuje nad pojmovnim. Do podobnih ugotovitev sta prišli Lipovec in Antolin Drešar (2015), ki sta se osredotočili le na risbe potence. 


\section{Zaključek}

Pri matematiki lahko risbe, ki jih izdelajo učenci, služijo kot uvid v matematično razumevanje učencev (MacDonald, 2013; Thom in McGarvey, 2015). Risbe tako predstavljajo neodvisno sredstvo matematične komunikacije, ki pa je zahtevno za interpretacijo, saj lahko več subjektivnih faktorjev interpretatorja vpliva na rezultat (Dreyfus, 1995). Določanje, katera risba spada pod primerno reprezentacijo danega pojma in katera ne, sodi zato med zahtevna opravila (diSessa, 2004).

V naši raziskavi smo ugotovili, da dijaki oz. študenti, bodoči učitelji, z risbo ustrezno ponazarjajo nekatere osnovne matematične pojme (odštevanje, oklepaj, potenca in ulomek). Potrdili smo predpostavko, da so razlike v ustreznosti risb povezane $\mathrm{z}$ abstraktnostjo pojma in $\mathrm{z}$ načinom izobraževanja. Risbe so bile bolj ustrezne, če so prikazovale manj abstraktne pojme. Dodatno so udeleženci, ki se izobražujejo za bodoče učitelje razrednega pouka, v večji meri podajali ustrezne risbe.

Smisel grafičnih reprezentacij, kamor sodijo tudi risbe, je pravzaprav $\mathrm{v}$ tem, da pomagajo učencu vizualizirati matematične pojme in s tem poglobiti njegovo razumevanje le-teh. Učitelji matematike med vizualizacijo in vizualno reprezentacijo večkrat ne vidijo bistvene razlike, kar pa ne velja za učence. Učenci namreč večkrat ne vidijo tega, kar vidi učitelj in za kar je učitelj prepričan, da je iz reprezentacije očitno. Zato se zdi pomembno, da učencem dovolimo oz. jih celo spodbujamo k izražanju matematičnega znanja tudi skozi risbo. Risbe kot raziskovalno orodje (ali pomagalo učitelju pri vpogledu v učenčevo razumevanje) se še niso dovolj uveljavile, čeprav je vlogi različnih reprezentacij pri učenju in poučevanju matematike namenjeno mnogo pozornosti. Upamo, da bodo izsledki naše raziskave spodbudili tudi druge $\mathrm{k}$ uporabi risb $\mathrm{z}$ namenom vpogleda $\mathrm{v}$ način matematičnega razmišljanja.

$\mathrm{Na}$ osnovi rezultatov predlagamo a) več matematičnih aktivnosti, ki vključujejo risanje, b) učenci naj risbe oblikujejo samostojno, c) učitelji naj ne vrednotijo učenčevih risb kot pravilne oz. napačne ter d) s pomočjo risb naj učitelj individualizira delo v razredu. Čeprav naši podatki podajajo primere (bolj ali manj ustreznih) risb le za nekatere osnovne matematične pojme, upamo, da je kategorizacija, ki je podana v tabeli 2 uporabna tudi za druge matematične pojme. Če bodo učitelji bolj pozorni na risbe, ki jih oblikujejo učenci pri matematiki, in bodo dodatno te risbe tudi klasificirali, lahko pouk matematike postane bolj individualiziran in s tem učinkovitejši.

\section{Literatura}

Arcavi, A. (2003). The role of visual representations in the learning of mathematics. Educational Studies in Mathematics, 52(3), 215-241.

Archer, K., Savage, R., Sangera-Sidhu, S., Wood, E., Gottardo, A. in Chen, V. (2014). Examining the effectiveness of technology use in classrooms: A tertiary meta-analysis. Computers \& Education, 78, 140-149.
Antolin Drešar, D. in Lipovec, A. (2015). Slovenian pupils' conceptions of the mathematician profession. $\mathrm{V} \mathrm{O}$. Fleischmann (ur.), The teaching profession: New challenges - new identities (str. 21-29)? Zürich, Švica: LIT.

Badillo, E., Font, V. in Edo, M. (2015). Analysing the responses of 7-8 year olds when solving partitioning problems. International Journal of Science and Mathematics Education, 13, 811-836.

Bakker, A. in Gravemeijer, K. (2004). Learning to reason about distribution. V D. Ben-Zvi in J. Garfield (ur.), The challenge of developing statistical literacy, reasoning, and thinking (str. 147-168). Dordrecht, Nizozemska: Kluwer.

Ball, D. L., Thames, M. H. in Phelps, G. (2008). Content knowledge for teaching: What makes it special? Journal of Teacher Education, 59, 389-407.

Beitzel, B. D., Staley, R. K. in Dubois, N. F. (2011). The (in)effectiveness of visual representations as an aid to solving probability word problems. Effective Education, 3(1), 11-22.

Binterová, B., Petrášková, V. in Komínková, O. (2014). The CLIL method versus pupils' results in solving mathematical word problems. The New Educational Review, 38, 238-249.

Bruner, J. (1964). The course of cognitive growth. American Psychologist, 1(19), 1-15.

Confrey, J. in Smith, E. (1995). Splitting, covariation, and their role in the development of exponential functions. Journal for Research in Mathematics Education, 26(1), 66-86.

Crooks, N. M. in Alibali, M. W. (2014). Defining and measuring conceptual knowledge in mathematics. Developmental Review, 34, 344-377.

Černela, R. (2014). Predstave učencev o matematikih (neobjavljeno diplomsko delo) [Childrens' conceptions of the mathematicians (unpublished bacelors thesis)]. Pedagoška fakulteta Univerze v Mariboru, Slovenija.

de Bock, D., van Dooren, W., Janssens, D. in Verschaffel, L. (2007). The illusion of linearity: From analysis to improvement. New York, NY, ZDA: Springer.

Depaepe, F., Torbeyns, J., Vermeersch, N., Janssens, D., Janssens, R., Kelchtermans, G. in Van Dooren, W. (2015). Teachers' content and pedagogical content knowledge on rational numbers: A comparison of prospective elementary and lower secondary school teachers. Teaching and Teacher Education, 47, 82-92.

diSessa, A. A. (2004). Metarepresentation: Native competence and targets for instructions. Cognition and Instruction, 22(3), 293-331.

Dixon, J. K., Andreasen, J. B., Avila, C. L., Bawatneh, Z., Deichert, D. L., Howse, T. D. in Turner, M. S. (2014). Redefining the whole: Common errors in elementary

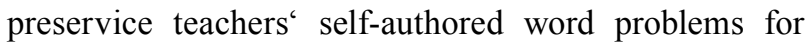
fraction subtraction. Investigations in Mathematics Learning, 7(1), 1-22.

Doerr, H. M. (2006). Teachers' ways of listening and responding to students' emerging mathematical models. ZDM Mathematics Education, 38(2), 255-268. 
Doorman, L. M. (2002). How to guide students? A reinvention course on modelling motion. V L. Fou-Lai (ur.), Common sense in Mathematics education (str. 97-114). Taipei, Taiwan: National Taiwan Normal University.

Dreyfus, T. (1995). Imagery for diagrams. V R. Sutherland in J. Mason (ur.), Exploiting mental imagery with computers in mathematics education (str. 3-19). Berlin, Nemčija: Springer.

Eldén, S. (2012). Inviting the messy: Drawing methods and children's voices. Childhood, 20(1), 66-81.

English, L. D. (1993). Children's strategies for solving twoand three-dimensional combinatorial problems. Journal for Research in Mathematics Education, 24(3), 255-273.

Freudenthal, H. (1991). Revisiting mathematics education: China lectures. Dordrecht, Nizozemska: Kluwer Academic.

Guillemin, M. (2004). Understanding illness: Using drawings as a research method. Health Policy \& Services, 14(2), 272-289.

Güler, G. in Çiltaş, A. (2011). The visual representation usage levels of mathematics teachers and students in solving verbal problems. International Journal of Humanities and Social Science, 1(11), 145-154.

Hesse-Biber, S. N. in Leavy, P. (2004). Distinguishing qualitative research. V S. N. Hesse-Biber in P. Leavy (ur.), Approaches to qualitative research: $A$ reader on theory and practice (str. 1-15). New York, NY, ZDA: Oxford University Press.

Hiebert, J. in LeFevre, P. (1986). Conceptual and procedural knowledge in mathematics: an introductory analysis. V J. Hiebert (ur.), Conceptual and procedural knowledge: The case of mathematics (str. 1-27). Hillsdale, MI, ZDA: Lawrence Erlbaum Associates.

Hill, H. C., Rowan, B. in Ball, D. L. (2005). Effects of teachers' ${ }^{6}$ mathematical knowledge for teaching on student achivement. American Educational Research Journal, 42, 371-406.

Hsieh, H.-F. in Shannon, S.E. (2005). Three approaches to qualitative content analysis. Qualitative Health Research, 15(9), 1277-1288.

Isik, C. in Kar, T. (2012). An error analysis in division problems in fractions posed by pre-service elementary mathematics teachers. Educational Sciences: Theory and Practice, 12(3), 2303-2309.

Kearney, K. S. in Hyle, A. E. (2004). Drawing out emotions: The use of participant-produced drawings in qualitative inquiry. Qualitative Research, 4(3), 361-382.

Kokol Voljč, V. (1995). Razvoj matematičnih pojmov - empirično ali teoretično? [Development of the mathematical concepts - empirical or theoretical?]. Educa, 5(1-2), 21-28.

Leikin, M., Waisman, I., Shaul, S. in Leikin, R. (2014). Brain activity associated with translation from a visual to a symbolic representation in algebra and geometry. Journal of Integrative Neuroscience, 13(1), 35-59.

Levstek, T., Bregant, T. in Podlesek, A. (2013). Razvoj aritmetičnih sposobnosti [Development of arithmetical abilities]. Psihološka obzorja, 22, 115-121.
Lipovec, A. in Antolin Drešar, D. (2015). Shematic and pictorial representations of exponentiation. V O. Fleischmann (ur.). The teaching profession: New challenges - new identities? (str. 137-144). Zürich, Švica: LIT.

Lipovec, A. in Ferk, E. (2012). Matematično znanje za poučevanje [Mathematical knowledge for teaching]. Pedagoška obzorja, 27(1/2), 53-70.

Lipovec A., Podgoršek, M. in Antolin Drešar, D. (2015). Grafične predstavitve nekaterih elementarnih matematičnih pojmov [Graphic representations of some mathematical concepts]. Pedagoška obzorja, 30(3/4), 19-35.

Lowrie, T. in Diezman, C. M. (2011). Solving graphics tasks: Gender differences in middle-school students. Learning and Instruction, 21(1), 109-125.

MacDonald, A. (2013). Using children's representations to investigate meaning-making in mathematics. Australasian Journal of Early Childhood, 38(2), 65-73.

Marjanovič Umek, L. (2011). Otroška risba [Children's drawing]. V L. Marjanovič Umek in M. Zupančič, M. (ur.) Razvojna psihologija: Izbrane teme (str. 127-155). Ljubljana: Znanstvena založba Filozofske fakultete.

Maxwell, E. A. (1995). Fallacies in mathematics. Cambridge, Združeno kraljestvo: Cambridge University Press.

Mitchelmore, M. in White, P. (2004). Abstraction in mathematics and mathematics learning. V M. J. Hoines in A. B. Fuglestad (ur.), Proceedings of the 28th conference of the International Group for the Psychology of Mathematics Education: Vol. 3 (str. 329-336). Bergen, Norway: Bergen University College.

Mitchelmore, M. C. in White, P. (1995). Abstraction in mathematics: Conflict, resolution and application. Mathematics Education Research Journal, 7(1), 50-68.

Nelsen, R. B. (2000). Proofs without words: Exercises in visual thinking. Washington, DC, ZDA: Mathematical Association of America.

Picker, S. H. in Berry, J. S. (2000). Investigating pupils image of mathematicians. Educational Studies in Mathematics, 43(1), 65-94.

Pirie, C. in Kieren, T. (1994). Growth in mathematical understanding: How can we characterise it and how can we represent it? Educational Studies in Mathematics, 26(2/3), 165-190.

Presmeg, N. C. (1992). Prototypes, metaphors, metonymies and imaginative rationality in high school mathematics. Educational Studies in Mathematics, 23(6), 595-610.

Rittle-Johnson, B., Schneider, M. in Star, J. R. (2015). Not a one-way street: Bidirectional relations between procedural and conceptual knowledge of mathematics. Education Psychological Review, 27(4), 587-597.

Rittle-Johnson, B. in Siegler, R. S. (1998). The relation between conceptual and procedural knowledge in learning mathematics: A review. V C. Donlan (ur.), The development of mathematical skills (str. 75-110). London, Združeno kraljestvo: Psychology Press.

Rivera, F. D. (2014). From math drawings to algorithms: Emergence of whole number operations in children. ZDM Mathematics Education, 46(1), 59-77. 
Rose, G. (2014). On the relation between 'visual research methods' and contemporary visual culture. Sociological Review, 62(1), 24-46.

Saban, A. in Akbulut, M. G. (2012). An investigation of primary school student's perceptions of violence revealed through their drawings. Turkish Journal of Education, 1(1), 21-37.

Skemp, R. R. (1976). Relational understanding and instrumental understanding. Mathematics Teaching, 77, 20-26.

Sowell, E. J. (1989). Effects of manipulative materials in mathematics instruction. Journal for Research in Mathematics Education, 20(5), 498-505.

Star, J. R. (2005). Reconceptualizing procedural knowledge. Journal for Research in Mathematics Education, 36(5), 404-411.

Šali, B. (1961). Rorscachova psihodiagnostika [Rorschach psychodiagnostic]. Kranj, Slovenija: Zavod za izobraževanje kadrov in proučevanje organizacije dela.

Thom, J. S. in McGarvey, L. M. (2015). The act and artifact of drawing(s): Observing geometric thinking with, in, and through children's drawings. ZDM Mathematics Education, 47(3), 465-481.

Van den Heuvel-Panhuizen, M. (2003). The didactical use of models in Realistic Mathematics Education: An example from a longitudinal trajectory on percentage. Educational Studies in Mathematics, 54(1), 9-35.

Van Steenbrugge, H., Lesage, E., Valcke, M. in Desoete, A. (2014). Preservice elementary school teachers' knowledge of fractions: A mirror of students' knowledge? Journal of Curriculum Studies, 46(1), 138-161.

Zhang, Y. in Wildemuth, B. M. (2009). Qualitative analysis of content. V Wildemuth, B. (ur.), Applications of social research methods to questions in information and library science (str. 308-319). Westport, CT, ZDA: Libraries Unlimited. 